\title{
PENDAPATAN, NILAI TAMBAH, DAN PEMASARAN AGROINDUSTRI TAHU HOUSE OF TOFU DI KOTA BANDAR LAMPUNG
}

(Income, added value, and marketing of Tofu Agroindustry 'The House of Tofu' in Bandar Lampung City)

Anis Hasna Syafitri, Wan Abbas Zakaria, Yaktiworo Indriani

Jurusan Agribisnis, Fakultas Pertanian, Universitas Lampung, J1. Prof. Dr. Soemantri Brojonegoro No. 1

Bandar Lampung 35145, e-mail : wanabas.zakaria@fp.unila.ac.id

\begin{abstract}
This study aims to analyze income, added value of tofu soybeans, tofu product marketing channels, and marketing margins. The research method used is the case study method in the Agroindustrial House of Tofu, Way Halim Permai Village, Way Halim District, Bandar Lampung City. The location of the research was determined deliberately with the consideration that Way Halim District is the center of tofu agroindustry in Bandar Lampung City and House of Tofu Agroindustry with the highest production in Way Halim Regency. This research was conducted in January - March 2020. The data analysis method used in this research was qualitative and quantitative descriptive analysis. The results showed that the income of producing each tofu product was profitable because $R / C>1$ and the agroindustry had positive added value. The marketing channel consists of three channels. The market share for all types of tofu in the marketing process of the House of Tofu Agroindustry is more than 50\%.
\end{abstract}

Key words : agroindustry, income, marketing, production, tofu.

\section{PENDAHULUAN}

Sektor industri pertanian merupakan suatu sistem pengelolaan secara terpadu antara sektor industri dengan sektor pertanian guna mendapatkan nilai tambah produk hasil pertanian. Sektor industri pertanian juga dapat menjadi basis dalam mengembangkan kegiatan ekonomi perdesaan melalui pengembangan usaha berbasis pertanian yaitu agribisnis dan agroindustri. Sektor pertanian berperan besar dalam menjaga laju pertumbuhan ekonomi nasional dengan pertumbuhan yang terus positif dan konsisten (Antara 2009).

Agroindustri merupakan suatu usaha untuk meningkatkan efisiensi sektor pertanian hingga menjadi kegiatan yang sangat produktif melalui proses modernisasi pertanian. Modernisasi di sektor industri dalam skala nasional akan mempengaruhi pendapatan ekspor lebih besar dan dapat meningkatkan penerimaan (Saragih 2010).

Agroindustri mengolah bahan mentah yang berasal dari pertanian menjadi bahan jadi maupun setengah jadi. Agroindustri memanfaatkan teknologi, tenaga manusia, serta bahan-bahan penunjang lainnya untuk menghasilkan nilai tambah dari produk pertanian agar dapat meningkatkan keuntungan. Salah satu agroindustri yang banyak diminati adalah agroindustri tahu.
Agroindustri tahu yang ada di Kelurahan Way Halim Permai adalah Agroindustri Tahu House of Tofu (HOT). Usaha ini berlokasi di Jl. Pulau Batam, Way Halim, Bandar Lampung dan pemilik dari industri rumahan tahu HOT adalah Bapak A. Agroindustri Tahu HOT merupakan pabrik yang sudah berdiri sejak tahun 1994, industri ini mengolah kedelai menjadi tahu kotak putih besar dan kecil dan tahu kotak kuning besar kecil dari tahun 1994 sampai dengan tahun 2013. Pada tahun 2014, industri ini menambah jenis produknya yaitu tahu bulat.

Bahan baku utama dalam pembuatan tahu adalah kedelai, dan beberapa bahan baku penunjang. Kedelai memiliki arti penting dalam industri pangan dan pakan. Tidak hanya sebagai bahan baku industri dan pakan, tetapi juga mampu memperbaiki gizi masyarakat bila dimasukkan dalam pola konsumsi sehari-hari, karena mengandung kadar protein yang tinggi, vitamin dan mineral serta sumber lemak, baik dalam bentuk segar maupun olahan seperti tempe, tahu, kecap, tauco, dan sebagainya (Shafira, Lestari, Affandi 2018).

Bahan baku yang tersedia dalam kuantitas dan kualitas yang cukup dan waktu yang tepat, akan sangat dibutuhkan selama kegiatan produksi berlangsung. Dengan adanya kegiatan produksi atau pengolahan yang baik, maka akan 
menghasilkan pendapatan yang tinggi. Perbedaan nilai suatu produk dari bahan baku menjadi bahan jadi menghasilkan nilai tambah.

Pemasaran tahu dari Agroindustri Tahu HOT di sekitar kota Bandar Lampung. Tingkat persaingan antar- pengusaha tahu di Kecamatan Way Halim dalam memperoleh pasar yang luas semakin kuat. Harga tahu yang relatif murah dan sifat produk yang mudah rusak menyebabkan perlu dilakukannya pemasaran secara efisien dan cepat. Keberhasilan suatu industri terletak pada pemasaran yang dilakukan, apabila suatu produk tersebut sudah bagus kualitas dari bahannya serta kuantitas harganya, tetapi tidak dipasarkan dengan baik, maka pemasarannya tersebut belum efesien. Keuntungan yang didapat oleh setiap lembaga pemasaran disebut juga dengan marjin pemasaran. Berdasarkan latar belakang tersebut, maka penelitian ini bertujuan untuk menganalisis pendapatan, nilai tambah, dan pemasaran pada Agroindustri Tahu HOT.

\section{METODE PENELITIAN}

Metode penelitian yang digunakan adalah metode studi kasus. Penelitian ini dilakukan di Kecamatan Way Halim, Kota Bandar Lampung. Pemilihan lokasi penelitian menggunakan metode purposive, yaitu dipilih secara sengaja dengan pertimbangan, bahwa Kecamatan Way Halim merupakan sentra agroindustri tahu di Kota Bandar Lampung. Selain itu, Agroindustri Tahu HOT merupakan agroindustri tahu terbesar dan tertua di Kecamatan Way Halim yang memiliki kapasitas produksi $1.000 \mathrm{~kg}$ kedelai per hari, dengan memproduksi banyak jenis tahu yaitu tahu putih besar dan kecil, tahu kuning besar dan kecil, serta tahu bulat.

Responden dalam penelitian ini terdiri dari pemilik Agroindustri Tahu HOT dan responden pedagang yang terdiri dari 30 orang yang terdiri dari 5 pedagang besar, 15 pedagang pengecer, dan 10 pedagang keliling. Pengumpulan data penelitian dilakukan pada Bulan Januari - Maret 2020. Penentuan responden pedagang dilakukan secara snowball sampling, yaitu informasi dari produsen tahu, kemudian menelusuri pedagang - pedagang yang terkait hingga sampai pada konsumen akhir.

Sumber penelitian ini berasal dari dua jenis data yaitu data primer dan data sekunder. Data primer adalah data yang diperoleh langsung dari subjek penelitian, dalam hal ini peneliti memperoleh data atau informasi langsung dengan menggunakan kuesioner yang ditanyakan kepada pemilik Agroindustri Tahu HOT. Data sekunder diperoleh dari penelitian terdahulu, studi literatur, laporanlaporan, jurnal penelitian dan pustaka lainnya yang berhubungan dengan penelitian ini serta lembaga/instansi terkait seperti Badan Pusat Statistik Provinsi Lampung, Badan Pusat Statistik, Dinas Perindustrian Kota Bandar Lampung, dan Dinas Perdagangan Provinsi Lampung. Penelitian ini menggunakan metode deskriptif kualitatif dan kuantitatif. Metode deskriptif kualitatif digunakan untuk menganalisis saluran pemasaran. Metode deskriptif kuantitatif digunakan untuk menganalisis pendapatan, nilai tambah, serta marjin pemasaran Agroindustri Tahu HOT.

Agroindustri Tahu HOT menggunakan perhitungan biaya bersama atau joint cost untuk menghasilkan beberapa produk menggunakan alat dan mesin yang sama. Agroindustri tersebut mengolah bahan baku berupa kedelai menjadi beberapa jenis tahu yaitu, tahu putih besar dan kecil, tahu kuning besar dan kecil, serta tahu bulat, tidak hanya bahan baku, akan tetapi untuk biaya tetap dan biaya variabelnya digunakan secara bersama saat melakukan proses produksi. Maka dari itu, metode joint cost yang dilakukan pada Agroindustri Tahu HOT adalah metode satuan fisik. Menurut Mulyadi (2009) metode satuan fisik yaitu menentukan harga produk bersama sesuai dengan manfaat yang ditentukan oleh masing-masing produk akhir, dalam metode ini joint cost dialokasikan kepada produk atas dasar koefisien fisik kuantitas produksi yang terdapat dalam masing-masing produk. Metode satuan fisik diharuskan bahwa produk bersama yang dihasilkan harus dapat diukur dengan satuan ukuran pokok yang sama dengan koefisen fisik yang dinyatakan dalam satuan berat. Selanjutnya mengalokasikan total joint cost dengan metode satuan fisik diantara produk bersama berdasarkan proporsi tersebut, dengan rumus sebagai berikut.

Perhitungan joint cost metode satuan fisik =

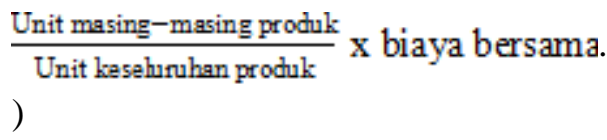

Analisis pendapatan yang dilakukan pada Agroindustri Tahu HOT dengan hitungan per bulan. Pendapatan dari agroindustri ini dapat diketahui dengan melakukan analisis penerimaan yang didapat dan biaya-biaya yang dikeluarkan selama agroindustri berjalan. Untuk penerimaan 
dapat dirumuskan sebagai berikut (Soekartawi 2000).

$\mathrm{TR}=\mathrm{P} \cdot \mathrm{Q}$

Keterangan :

$\mathrm{TR}=$ total revenue $($ total penerimaan) $(\mathrm{Rp} / \mathrm{kg})$

$\mathrm{P} \quad=$ price (harga produk) $(\mathrm{Rp} / \mathrm{kg})$

$\mathrm{Q}$ = quantity (jumah produk) $(\mathrm{kg})$

Pendapatan suatu usaha dapat diketahui dengan adanya penerimaan dan biaya, yang secara matematis dapat dirumuskan sebagai berikut.

$\Pi=\mathrm{TR}-\mathrm{TC}$

Keterangan :

$\Pi \quad=$ pendapatan $(\mathrm{Rp})$

$\mathrm{TR}=$ total revenue (total penerimaan) $(\mathrm{Rp})$

$\mathrm{TC}=$ total cost (total biaya) (Rp)

Setelah menghitung analisis pendapatan, maka dilakukan analisis $\mathrm{R} / \mathrm{C}$ rasio untuk melihat keuntungan suatu usaha. Analisis R/C rasio merupakan suatu perhitungan perbandingan antara total penerimaan dengan total biaya. $\mathrm{R} / \mathrm{C}$ rasio secara matematis dapat dirumuskan (Soekartawi 2000).

$\mathrm{R} / \mathrm{C}=\mathrm{TR} / \mathrm{TC}$

Keterangan:

$\mathrm{R} / \mathrm{C}=$ Nisbah penerimaan dan biaya

$\mathrm{TR}=$ Total revenue (total penerimaan) $(\mathrm{Rp})$

$\mathrm{TC}=$ Total cost (total biaya) $(\mathrm{Rp})$

Kriteria pengambilan keputusan menurut (Soekartawi 2000) adalah sebagai berikut :

(1) Jika R/C > 1, maka suatu usaha mengalami untung karena penerimaan lebih besar daripada biaya.

(2) Jika $\mathrm{R} / \mathrm{C}<1$, maka suatu usaha mengalami rugi karena penerimaan lebih kecil daripada biaya.

(3) Jika $\mathrm{R} / \mathrm{C}=1$, maka suatu usaha mengalami impas/sama karena penerimaan sama dengan biaya.

Analisis nilai tambah dihitung dengan cara nilai output dikurangi harga bahan baku dan sumbangan input lain. Analisis nilai tambah dilakukan untuk mengetahui besarnya nilai tambah yang didapat dari pengolahan kedelai menjadi tahu selama proses produksi (Hayami et al 1987). Perhitungan nilai tambah dapat dilihat sebagai berikut.
NT = Nilai output - harga bahan baku - sumbangan input lain

Dengan kriteria penilaian sebagai berikut.

a. Jika NT > $>$, berarti agroindustri tahu memberikan nilai tambah (positif).

b. Jika NT < 0, berarti agroindustri tahu tidak memberikan nilai tambah (negatif).

Producer's share digunakan Untuk mengetahui efisiensi pemasaran tahu. Producer's share atau tinggi rendahnya marjin yang diterima oleh produsen dari harga jual ditingkat konsumen akhir merupakan indikator efisiensi pemasaran. Marjin pemasaran adalah perbedaan harga pada tingkat produsen $(\mathrm{Pf})$ dengan harga di tingkat pengecer (Pr) yang terdiri dari keuntungan dan biaya (Hasyim 2012). Marjin pemasaran dapat dihitung dengan menggunakan rumus sebagai berikut.

$\mathrm{Mji}=\mathrm{Psi}-\mathrm{Pbi}$

Keterangan :

$\mathrm{Mji}=$ Marjin lembaga pemasaran tingkat ke-i

Psi $=$ Harga penjualan lembaga pemasaran tingkat ke-i $(\mathrm{i}=1,2,3, \ldots ., \mathrm{n})$

$\mathrm{Pbi}=$ Harga pembelian lembaga pemasaran tingkat ke-i

Rumus total marjin pemasaran sebagai berikut.

$\mathrm{Mji}=\operatorname{Pr}-\mathrm{Pf}$

Keterangan :

Mji = Total marjin pemasaran

$\operatorname{Pr}=$ Harga pada tingkat konsumen

Pf = Harga pada tingkat produsen

Penyebaran marjin pemasaran dapat dilihat berdasarkan presentase keuntungan terhadap biaya pemasaran (Ratio Profit Margin) pada masing masing lembaga pemasaran, yang dirumuskan sebagai berikut.

$\mathrm{RPM}=\frac{\pi \mathrm{i}}{\mathrm{bti}}$

Keterangan :

Bti = Biaya pemasaran lembaga pemasaran tingkat ke-i

Пi = Keuntungan lembaga pemasaran tingkat kei

Abidin, Harahab dan Asmarawati (2017) menyatakan bahwa saluran pemasaran dianggap efisien apabila saluran pemasaran tersebut mempunyai producer's share lebih dari 50 persen. 
Producer's share dirumuskan (Asmarantaka 2012).

Producer's share $=\frac{\mathrm{Pf}}{\mathrm{Pr}} \times 100 \%$

$$
\begin{array}{ll}
\text { Keterangan : } & \\
\text { Producer's share } & =\begin{array}{l}
\text { Bagian yang diterima } \\
\text { produsen }
\end{array} \\
& =\begin{array}{l}
\text { Harga tahu di tingkat } \\
\text { produsen }
\end{array} \\
& =\begin{array}{l}
\text { Harga tahu di tingkat } \\
\text { konsumen }
\end{array}
\end{array}
$$

\section{HASIL DAN PEMBAHASAN}

\section{Karakteristik Responden}

Pemilik Agroindustri Tahu HOT yaitu Bapak A berumur 57 tahun. Pendidikan terakhir Bapak A adalah lulusan SMA. Pengalaman yang dimiliki dalam mengelola Agroindustri Tahu HOT yaitu selama 25 tahun dengan jumlah tanggungan keluarga delapan orang. Agroindustri ini termasuk dalam skala usaha besar, yang dapat dilihat dari modal awal dibukanya usaha adalah sebesar Rp50.000.000,00 pada tahun 1994, jumlah karyawan saat ini, yaitu berjumlah 23 orang dan kondisi agroindustri sudah memadai dengan adanya alat dan mesin yang modern.

Responden pedagang pada penelitian ini terdiri dari pedagang besar, pedagang pengecer, dan pedagang keliling. Responden pedagang besar berjumlah 5 orang, pedagang pengecer 15 orang, dan pedagang keliling 10 orang. Umur responden pedagang besar berkisar antara 43-60 tahun dengan pengalaman usaha 7-15 tahun. Responden

\begin{tabular}{|c|c|c|c|c|c|c|}
\hline \multirow[b]{2}{*}{ Uraian } & \multirow[b]{2}{*}{ Satuan } & \multicolumn{5}{|c|}{ Biaya rata-rata produksi per bulan } \\
\hline & & $\begin{array}{l}\text { Tahu putih } \\
\text { besar }\end{array}$ & $\begin{array}{l}\text { Tahu putih } \\
\text { kecil }\end{array}$ & $\begin{array}{l}\text { Tahu kuning } \\
\text { besar }\end{array}$ & $\begin{array}{c}\text { Tahu kuning } \\
\text { kecil }\end{array}$ & Tahu bulat \\
\hline Joint Cost & $\%$ & 30 & 19 & 30 & 19 & 2 \\
\hline \multicolumn{7}{|l|}{ a. Biaya Tunai } \\
\hline Kedelai & $\mathrm{kg}$ & $53.084 .293,41$ & $32.978 .206,59$ & $53.084 .293,41$ & $32.978 .206,59$ & $11.475 .000,00$ \\
\hline $\begin{array}{l}\text { Pelet kayu (bahan } \\
\text { bakar) }\end{array}$ & $\mathrm{kg}$ & $10.217 .144,00$ & 6.347.321,67 & $10.217 .144,00$ & $6.347 .321,67$ & $621.068,66$ \\
\hline $\begin{array}{l}\text { Bungkus plastik } \\
\text { t.kotak besar }\end{array}$ & $\mathrm{kg}$ & $4.387 .500,00$ & 0 & $4.387 .500,00$ & 0 & 0 \\
\hline $\begin{array}{l}\text { Bungkus plastik } \\
\text { t.kotak kecil }\end{array}$ & $\mathrm{kg}$ & 0 & $3.645 .000,00$ & 0 & $3.645 .000,00$ & 0 \\
\hline $\begin{array}{l}\text { Bungkus plastik } \\
\text { tahu bulat }\end{array}$ & $\mathrm{kg}$ & 0 & 0 & 0 & 0 & $864.000,00$ \\
\hline Garam & $\mathrm{kg}$ & $572.160,06$ & $355.450,01$ & $572.160,06$ & $355.450,01$ & $34.779,84$ \\
\hline Kunyit & $\mathrm{kg}$ & 0 & 0 & $2.664 .623,36$ & $1.655 .376,64$ & 0 \\
\hline Penyedap rasa & $\mathrm{kg}$ & 0 & 0 & 0 & 0 & $1.944,00$ \\
\hline Susu vanili & $\mathrm{kg}$ & 0 & 0 & 0 & 0 & 810,00 \\
\hline Plastik asoy sedang & pack & 0 & $360.369,40$ & 0 & $360.369,40$ & $35.261,19$ \\
\hline Plastik asoy besar & pack & $486.000,00$ & 0 & $486.000,00$ & 0 & 0 \\
\hline TKLK & $\mathrm{Rp}$ & $18.260 .685,22$ & $11.344 .309,42$ & $18.260 .685,22$ & $11.344 .309,42$ & $533.525,58$ \\
\hline Listrik & $\mathrm{Rp}$ & $2.119 .111,35$ & $1.316 .481,53$ & $2.119 .111,35$ & $1.316 .481,53$ & $128.814,24$ \\
\hline Pajak & $\mathrm{Rp}$ & $12.109,21$ & $7.522,75$ & $12.109,21$ & $7.522,75$ & 736,08 \\
\hline \multirow{2}{*}{\multicolumn{7}{|c|}{ b. Biaya }} \\
\hline & & & & & & \\
\hline Diperhitungkan & & & & & & \\
\hline Penyusutan & $\mathrm{Rp}$ & $963.034,14$ & $598.277,51$ & $1.028 .625,68$ & $639.025,75$ & $886.960,03$ \\
\hline $\begin{array}{l}\text { Total Biaya } \\
\text { Diperhitungkan }\end{array}$ & $\mathrm{Rp}$ & $963.034,14$ & $598.277,51$ & $1.028 .625,68$ & $639.025,75$ & $886.960,03$ \\
\hline Total Biaya $(a+b)$ & $\mathrm{Rp}$ & $90.102 .037,40$ & $56.952 .938,89$ & $92.832 .252,30$ & $58.649 .063,77$ & $14.582 .899,63$ \\
\hline
\end{tabular}
pedagang pengecer memiliki umur berkisar 29-60 tahun dengan pengalaman usaha 3-12 tahun. Untuk responden pedagang keliling memiliki umur berkisar antara 28-55 tahun dengan pengalaman usaha 2-15 tahun.

Tabel 1. Biaya Agroindustri Tahu HOT per bulan 
Penjualan tahu ini melibatkan 5 pedagang besar yang diambil dari 5 pasar, yaitu Pasar Way Kandis, Pasar Perumnas Way Halim, Pasar Panjang, Pasar Jatimulyo, dan Pasar Pasir Gintung. Agroindustri Tahu HOT menjual tahu ke pedagang besar dengan cara mengantarkannya ke masing-masing pasar. Pedagang besar memasarkan produk tahu putih dan tahu kuning ke pengecer. Pengecer tersebut terdiri dari pedagang warung dan pedagang keliling. Pengecer mengambil langsung ke pasar lalu menjualnya ke konsumen. Pedagang keliling mengambil langsung dari pabrik tahu untuk dijual secara keliling menggunakan alat transportasi motor ke daerah yang berbeda-beda.

\section{Analisis Pendapatan}

Hasil perhitungan pendapatan dan $\mathrm{R} / \mathrm{C}$ rasio untuk lima jenis tahu berbeda-beda sesuai dengan jenis dan jumlah produksinya. Hal ini terlihat dari pendapatan yang diperoleh, baik pendapatan atas biaya tunai dan biaya diperhitungkan. Biaya tunai adalah jumlah uang yang dikeluarkan langsung oleh pemilik agroindustri, terdiri dari biaya variabel, biaya tetap, dan biaya administrasi. Biaya variabel yaitu biaya yang dikeluarkan untuk pembelian kedelai, pelet kayu (bahan bakar), plastik untuk tahu kotak dan tahu bulat, garam, kunyit, susu vanili, penyedap rasa, dan plastik asoy. Biaya tetap yaitu biaya yang jumlahnya tetap, tidak tergantung kepada perubahan tingkat kegiatan dalam menghasilkan produk, terdiri dari biaya listrik dan tenaga kerja. Biaya administrasi yaitu biaya yang dikeluarkan untuk pembayaran pajak. Biaya yang diperhitungkan adalah jumlah uang yang tidak dibayarkan secara langsung dan hanya diperhitungkan sebagai biaya seperti biaya penyusutan alat dan mesin. Alat dan mesin digunakan secara bersama untuk lima jenis tahu, maka dari itu perhitungan penyusutan menggunakan perhitungan joint cost. Biaya yang dikeluarkan agroindustri dapat dilihat pada Tabel 1 .

Hasil analisis menunjukkan bahwa jenis tahu dengan pendapatan tertinggi yaitu tahu kuning besar, sedangkan jenis tahu dengan pendapatan terendah yaitu tahu bulat. Selanjutnya, tahu bulat memiliki penerimaan, biaya, dan pendapatan yang terendah, akan tetapi $\mathrm{R} / \mathrm{C}$ rasionya tertinggi.

Secara keseluruhan, Agroindustri Tahu HOT memiliki nilai $\mathrm{R} / \mathrm{C}$ atas biaya total yaitu $>1$ terhadap masing-masing produk tahu yang diproduksi, baik tahu kotak maupun tahu bulat. Hasil penelitian ini sejalan dengan Maulina,
Widyawati, Hakim (2020) tentang pendapatan dan efesiensi pemasaran industri tahu. Hasil penelitian tersebut menunjukkan bahwa industri tahu Mandiri yang dihasilkan sudah menguntungkan, karena nilai $\mathrm{R} / \mathrm{C}$ rasio yang diperoleh dari usaha industri sudah lebih dari satu artinya usaha industri tersebut sudah menguntungkan dan layak diusahakan. Pendapatan Agorindustri Tahu HOT dapat dilihat pada Tabel 2.

Penerimaan yang banyak didapatkan pada Agroindustri Tahu HOT adalah jenis tahu putih besar dan tahu kuning besar. Biaya tunai yang paling besar pada perhitungan pendapatan adalah biaya tahu kuning besar. Biaya tahu kuning besar berbeda dengan biaya tahu putih besar karena tahu kuning besar terdapat biaya tambahan untuk pembelian bahan penunjang berupa kunyit.

\section{Analisis Nilai Tambah}

Analisis nilai tambah yang dilakukan pada penelitian ini untuk mengetahui peningkatan nilai tambah dari pengolahan kedelai menjadi produk tahu, sehingga dapat memberikan nilai tambah yang tinggi bagi pemilik agroindustri. Perhitungan nilai tambah pada Agroindustri Tahu House of Tofu yaitu dengan memperhitungkan variabelvariabel seperti input, output, harga, pendapatan, nilai tambah, dan balas jasa untuk faktor produksi.

Pada Tabel 3 diketahui bahwa tahu putih besar dan tahu kuning besar memiliki input kedelai yang paling banyak, sedangkan tahu bulat memiliki input kedelai paling sedikit yaitu $1.687,50 \mathrm{~kg}$ per bulan, maka dari itu output yang didapatkan dari tahu putih besar dan tahu kuning besar paling banyak juga dibandingkan dengan ouput tahu bulat yang paling sedikit.

Nilai tambah tahu dihitung berdasarkan jenis masing-masing produk selama satu bulan. Berdasarkan Tabel 3 diketahui bahwa nilai tambah pada semua jenis tahu NT $>0$. Nilai tambah yang paling besar dari kelima jenis tahu, adalah tahu putih besar yaitu sebesar Rp33.961,21 per bulan, dengan rasio nilai tambah yaitu 78,68 persen. Agroindustri Tahu HOT layak untuk dikembangkan karena semua jenis tahu memberikan nilai tambah yang positif. Penelitian ini sejalan dengan penelitian Rosita, Hudoyo, dan Soelaiman (2019) yang menunjukkan bahwa nilai tambah yang dihasilkan pada penelitian tersebut memberikan nilai tambah yang positif sehingga usaha yang dijalankan dapat terus berkembang. 
Tabel 2. Pendapatan Agroindustri Tahu HOT per bulan

\begin{tabular}{lrrrrr}
\hline \multicolumn{1}{c}{ Uraian } & \multicolumn{1}{c}{$\begin{array}{c}\text { Tahu putih } \\
\text { besar }\end{array}$} & $\begin{array}{c}\text { Tahu putih } \\
\text { kecil }\end{array}$ & $\begin{array}{c}\text { Tahu kuning } \\
\text { besar }\end{array}$ & $\begin{array}{c}\text { Tahu kuning } \\
\text { kecil }\end{array}$ & \multicolumn{1}{c}{ Tahu bulat } \\
\hline Penerimaan (Rp/bulan) & $\begin{array}{r}\text { 336.960.000,00 } \\
\text { Persentase (\%) }\end{array}$ & $206.955 .000,00$ & $336.960 .000,00$ & $206.955 .000,00$ & $54.000 .000,00$ \\
Biaya tunai (Rp/bulan) & $89.139 .003,26$ & $56.354 .661,38$ & $91.803 .626,61$ & $58.010 .038,03$ & $13.695 .939,60$ \\
Biaya diperhitungkan & $963.034,14$ & $598.277,51$ & $1.028 .625,68$ & $639.025,75$ & $886.960,03$ \\
(Rp/bulan) & $90.102 .037,40$ & $56.952 .938,89$ & $92.832 .252,30$ & $58.649 .063,77$ & $14.582 .899,63$ \\
Jumlah biaya (Rp) & $247.820 .996,74$ & $150.600 .338,62$ & $245.156 .373,39$ & $148.944 .961,97$ & $40.304 .060,40$ \\
Pendapatan tunai & & & & & \\
(Rp/bulan) & $246.857 .962,60$ & $150.002 .061,11$ & $244.127 .747,70$ & $148.305 .936,23$ & $39.417 .100,37$ \\
$\begin{array}{l}\text { Pendapatan total } \\
\text { (Rp/bulan) }\end{array}$ & 3,78 & 3,67 & 3,67 & 3,57 & 3,94 \\
R/C tunai & 3,74 & 3,63 & 3,63 & 3,53 & 3,70 \\
R/C total & & & & & \\
\hline
\end{tabular}

Tabel 3. Nilai tambah Agroindustri Tahu HOT

\begin{tabular}{|c|c|c|c|c|c|c|}
\hline \multirow{2}{*}{$\begin{array}{lc}\text { No. } & \text { Variabel } \\
\text { Output, Input, dan Harga }\end{array}$} & \multicolumn{6}{|c|}{ Tahu } \\
\hline & & $\begin{array}{c}\text { Tahu putih } \\
\text { besar }\end{array}$ & $\begin{array}{c}\text { Tahu putih } \\
\text { kecil }\end{array}$ & $\begin{array}{c}\text { Tahu kuning } \\
\text { Besar }\end{array}$ & $\begin{array}{c}\text { Tahu kuning } \\
\text { kecil }\end{array}$ & Tahu bulat \\
\hline 1 Output $(\mathrm{Kg} / \mathrm{B} \ln )$ & A & $48.859,20$ & $30.353,40$ & $48.859,20$ & $30.353,40$ & $2.970,00$ \\
\hline 2 Bahan Baku (Kg/Bln) & B & $7.806,51$ & $4.849,74$ & $7.806,51$ & $4.849,74$ & $1.687,50$ \\
\hline 3 Tenaga Kerja (HOK/Bln) & $\mathrm{C}$ & 158,03 & 98,17 & 158,03 & 98,17 & 4,54 \\
\hline 4 Faktor Konversi & $d=a / b$ & 6,26 & 6,26 & 6,26 & 6,26 & 1,76 \\
\hline 5 Koefisien Tenaga Kerja & $\mathrm{e}=\mathrm{c} / \mathrm{b}$ & 0,020 & 0,020 & 0,020 & 0,020 & 0,003 \\
\hline 6 Harga Output $(\mathrm{Rp} / \mathrm{Kg})$ & $\mathrm{F}$ & $6.896,55$ & $6.818,18$ & $6.896,55$ & $6.818,18$ & $18.181,82$ \\
\hline $\begin{array}{l}\text { Upah Rata-Rata Tenaga } \\
\text { Kerja (Rp/HOK) }\end{array}$ & G & $115.555,56$ & $115.555,56$ & $115.555,56$ & $115.555,56$ & $117.617,65$ \\
\hline \multicolumn{7}{|l|}{$\begin{array}{l}\text { Pendapatan dan Nilai Tambah } \\
(\mathrm{Rp} / \mathrm{Kg})\end{array}$} \\
\hline $8 \begin{array}{l}\text { Harga Bahan Baku } \\
(\mathrm{Rp} / \mathrm{Kg})\end{array}$ & $\mathrm{H}$ & $6.800,00$ & $6.800,00$ & $6.800,00$ & $6.800,00$ & $6.800,00$ \\
\hline $9 \begin{array}{l}\text { Sumbangan Input Lain } \\
(\mathrm{Rp} / \mathrm{kg})\end{array}$ & I & $2.402,74$ & $2.604,35$ & $2.752,48$ & $2.954,09$ & $1.525,55$ \\
\hline 10 Nilai Output & $j=d \times f$ & $43.163,95$ & $42.673,45$ & $43.163,95$ & $42.673,45$ & $32.000,00$ \\
\hline 11 a. Nilai Tambah & $k=j-h-i$ & $33.961,21$ & $33.269,10$ & $33.611,47$ & $32.919,37$ & $23.674,45$ \\
\hline b. Rasio Nilai Tambah (\%) & $\mathrm{l}=\mathrm{k} / \mathrm{j}(\%)$ & 78,68 & 77,96 & 77,87 & 77,14 & 73,98 \\
\hline 12 a. Imbalan Tenaga Kerja & $\mathrm{m}=\mathrm{e} \times \mathrm{g}$ & $2.339,16$ & $2.339,16$ & $2.339,16$ & $2.339,16$ & 316,16 \\
\hline Bagian Tenaga Kerja & $\begin{array}{c}\mathrm{n}= \\
\mathrm{m} / \mathrm{k}(\%)\end{array}$ & 6,89 & 7,03 & 6,96 & 7,11 & 1,34 \\
\hline $\begin{array}{l}13 \text { a. Keuntungan } \\
\text { b. Tingkat Keuntungan }\end{array}$ & $\begin{array}{c}\mathrm{o}=\mathrm{k}-\mathrm{m} \\
\mathrm{p}=\mathrm{o} / \mathrm{k}(\%)\end{array}$ & $\begin{array}{c}31.622,05 \\
93,11\end{array}$ & $\begin{array}{l}30.929,94 \\
92,97\end{array}$ & $\begin{array}{l}31.272,31 \\
93,04\end{array}$ & $\begin{array}{l}30.580,21 \\
92,89\end{array}$ & $\begin{array}{r}23.358,28 \\
98,66\end{array}$ \\
\hline \multicolumn{7}{|l|}{ Balas Jasa untuk Faktor Produksi } \\
\hline 14 Margin & $q=j-h$ & $36.363,95$ & $35.873,45$ & $36.363,95$ & $35.873,45$ & $25.200,00$ \\
\hline a. Keuntungan & $\mathrm{r}=\mathrm{o} / \mathrm{q}(\%)$ & 86,96 & 86,22 & 86,00 & 85,24 & 92,69 \\
\hline b. Tenaga Kerja & $\mathrm{s}=\mathrm{m} / \mathrm{q}(\%)$ & 6,43 & 6,52 & 6,43 & 6,52 & 1,25 \\
\hline c. Input Lain & $\mathrm{t}=\mathrm{i} / \mathrm{q}(\%)$ & 6,61 & 7,26 & 7,57 & 8,23 & 6,05 \\
\hline
\end{tabular}

\section{Analisis Pemasaran}

Saluran pemasaran merupakan suatu saluran yang digunakan oleh produsen untuk menyalurkan produk dari produsen hingga ke konsumen, agar Agroindustri Tahu HOT mendapatkan keuntungan yang maksimal. Kegiatan pemasaran pada suatu agroindustri atau perusahaan tergantung pada saluran pemasaran yang ada dan banyaknya lembaga pemasaran yang ikut berperan dalam memasarkan produk. Saluran pemasaran pada Agroindustri Tahu HOT terbagi menjadi tiga saluran. Pertama, dari produsen ke pedagang besar yang mana agroindustri mengantarkan langsung ke pasar dengan adanya biaya transportasi kemudian ke pedagang pengecer, lalu ke konsumen. Kedua, dari produsen ke pedagang keliling yang mana pedagang ini mengambil langsung ke agroindustri kemudian ke konsumen. Ketiga, dari produsen langsung kepada konsumen. Saluran pemasaran 
tahu yang dilalui Agroindustri Tahu HOT, dapat dilihat pada Gambar 1, Gambar 2, Gambar 3, dan Gambar 4.

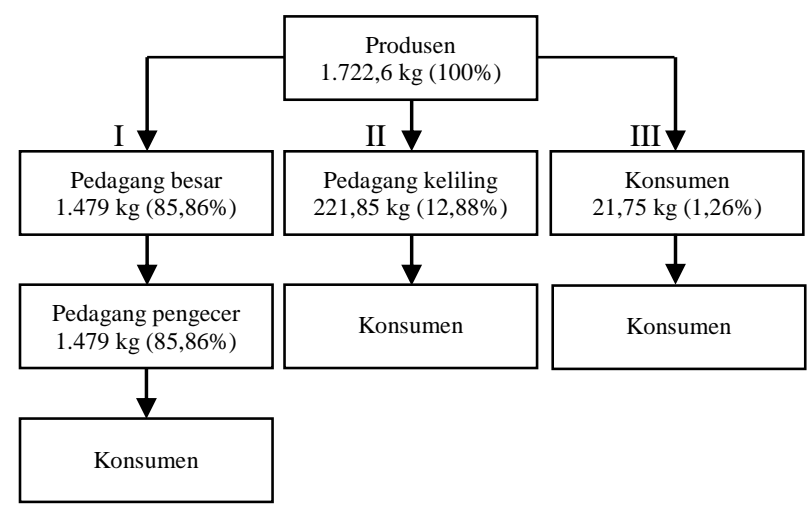

Gambar 1. Saluran pemasaran tahu putih besar

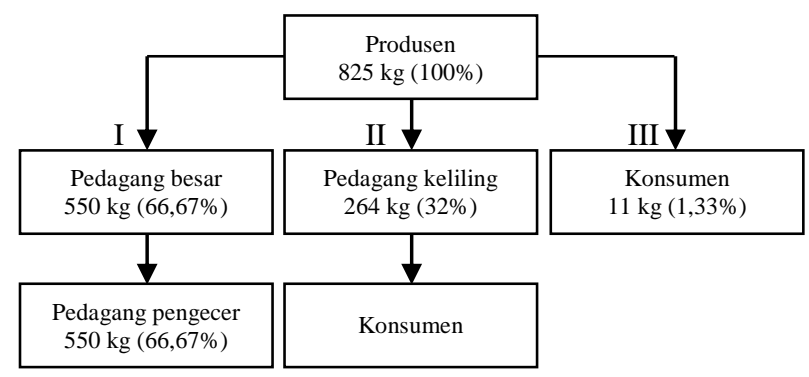

Gambar 2. Saluran pemasaran tahu putih kecil

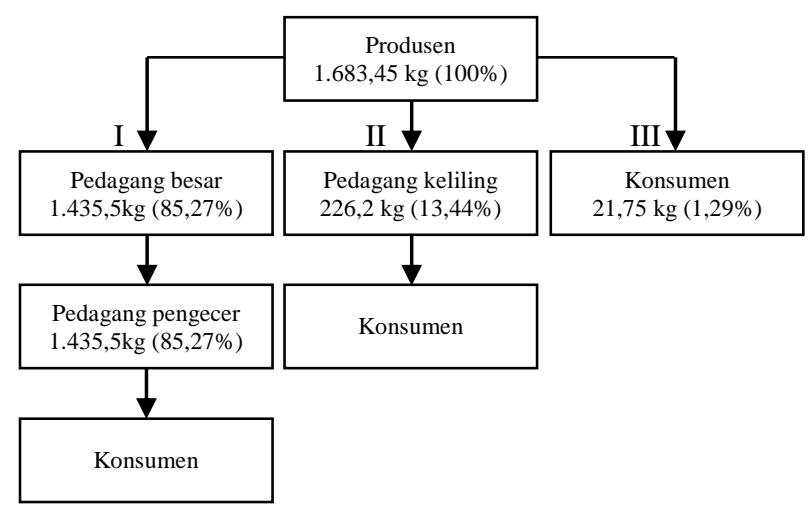

Gambar 3. Saluran pemasaran tahu kuning besar

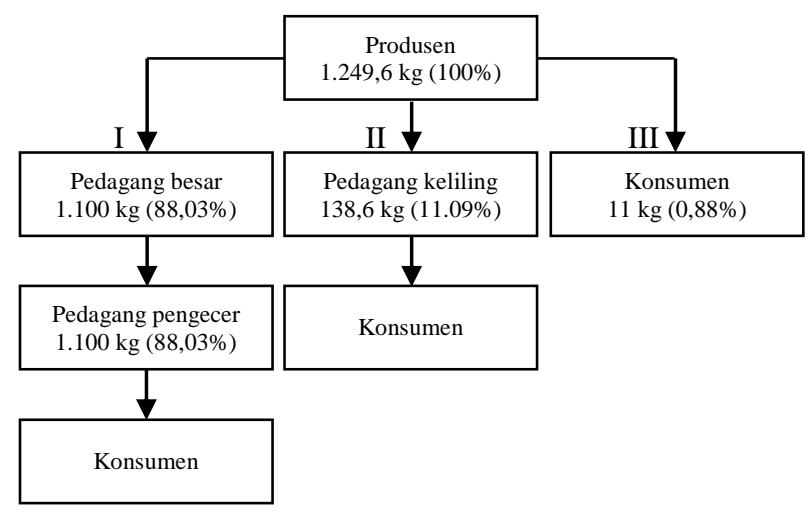

Gambar 4. Saluran pemasaran tahu kuning kecil
Saluran pemasaran pada tahu bulat hanya memiliki dua saluran, yaitu dari produsen ke pedagang keliling kemudian ke konsumen dan dari produsen langsung ke konsumen akhir. Hal tersebut dikarenakan pedagang pasar tidak mengambil jenis produk tahu bulat untuk dijual kembali.

Produksi yang dihasilkan dalam sehari untuk tahu bulat adalah sebanyak $55 \mathrm{~kg}$. Persentase banyaknya tahu bulat yang dijual ke pedagang keliling adalah sebesar 70 persen. Penjualan tahu bulat dari produsen ke konsumen langsung adalah sebesar 30 persen.

Hasil penelitian ini berbeda dengan hasil penelitian yang dilakukan oleh Narmin dan Antara (2016) mengenai analisis pendapatan dan pemasaran tahu pada industri "Afifah" di Kota Palu Sulawesi Tengah. Hasil penelitian tersebut menunjukkan bahwa saluran pemasaran yang terdapat pada industri "Afifah" hanya melibatkan dua saluran pemasaran. Saluran pertama, produsen menjual produk tahu ke pedagang pengecer dan pedagang pengecer menjual tahu ke konsumen akhir yang ada di pasar, saluran kedua produsen menjual tahu langsung ke konsumen. Pemasaran ini tidak dilakukan pemasaran kepada pedagang besar karena industri tersebut masih dalam skala kecil.

Pemasaran produk akan dikatakan efisien apabila barang atau produk yang disampaikan dari produsen ke konsumen mengeluarkan biaya yang serendah mungkin dan menghasilkan pembagian keuntungan bagi setiap pelaku pasar. Saluran pemasaran dianggap efisien apabila saluran pemasaran tersebut mempunyai producer's share lebih dari 50 persen (Abidin, Harahab dan Asmarawati 2017). Nilai producer's share atau pangsa pasar pada Agroindustri Tahu HOT untuk semua jenis tahu dari saluran I, saluran II, dan saluran III lebih dari 50 persen, artinya saluran pemasaran yang dilakukan pada agroindustri ini adalah efesien. Metode penelitian yang digunakan sama dengan metode penelitian Syarief, Lestari, Kasymir (2019), yang mana penelitiannya memiliki pangsa pasar lebih dari 50 persen.

\section{KESIMPULAN}

Usaha Agroindustri Tahu HOT menguntungkan dan layak untuk diusahakan, untuk semua jenis tahu memiliki R/C > 1. Agroindustri HOT memberikan nilai tambah positif sehingga usaha agroindustri layak untuk dikembangkan. Untuk saluran pemasaran yaitu terdapat tiga saluran pemasaran. Saluran I dari produsen ke pedagang 
besar ke konsumen, saluran II dari produsen ke pedagang keliling ke konsumen, dan saluran III dari produsen ke konsumen langsung. Producer's share pada kegiatan pemasaran untuk semua jenis tahu yaitu lebih dari 50 persen, sub sistem pemasaran berjalan secara efesien.

\section{DAFTAR PUSTAKA}

Abidin Z, Harahab N, dan Asmarawati, L. 2017. Pemasaran Hasil Perikanan. Tim UB Press. Malang.

Antara M. 2009. Pertanian, Bangkit atau Bangkrut?. Arti Foundation. Denpasar.

Asmarantaka RW. 2012. Pemasaran Agribisnis (Agrimarketing). IPB Press. Bogor.

Hasyim AI. 2012. Tataniaga Pertanian. Universitas Lampung. Bandar Lampung.

Hayami Y, Thosinori M, dan Masdjidin S. 1987. Agricultural marketing and processing in Upland Java, A Perspektif from a Sunda Village. Gramedia. Bogor.

Maulina CI, Widyawati, dan Hakim L. 2020.Analisis pendapatan dan efesiensi pemasaran industri tahu (Studi kasus: Industri Tahu Mandiri di Desa Punge Jurong Kecamatan Meuraxa Kota Banda Aceh). Jurnal Ilmiah Mahasiswa Pertanian, 5 (1) : 170-180.

http://www.jim.unsyiah.ac.id/JFP/article/dow nload/13582/6262 [4 Desember 2020].

Mulyadi. 2009. Akuntansi Biaya. Edisi Kelima. Cetakan kesembilan. Unit Penerbitan dan Percetakan Sekolah Tinggi Ilmu Manajemen YKPN Universitas Gajah Mada. Yogyakarta.
Narmin dan Antara, M. 2016. Analisis pendapatan dan pemasaran tahu pada industri "Afifah" di Kota Palu Sulawesi Tengah. E-J Agrotekbis, 4 (4) 468-478. https://media.neliti.com/media/publications/2 47101-analisis-pendapatan-dan-pemasarantahu-p-28b9305b.pdf [10 November 2019].

Rosita, Hudoyo A, dan Soelaiman A. 2019. Analisis usaha, nilai tambah, dan kesempatan kerja agroindustri tahu di Bandar Lampung. Jurnal Ilmu Ilmu Agribisnis, 7 (2) : 211-218. https://media.neliti.com/media/publications/2 50289-none-efee 7724.pdf $\quad[10 \quad$ November 2019].

Saragih B. 2010. Agribisnis : Paradigma Baru Pembangunan Ekonomi Berbasis Pertanian. IPB Press. Bogor.

Shafira F, Lestari DAH, dan Affandi MI. 2018. Analisis keragaan agroindustri tahu kulit di Kelurahan Gunung Sulah Kecamatan Way Halim Kota Bandar Lampung. Jurnal Ilmu Ilmu Agribisnis, 6 (3) : 279-287. http://jurnal.fp.unila.ac.id/index. php /JIA/article/download/3025/2414 [19 Oktober 2019].

Soekartawi. 2000. Pengantar Agroindustri. PT. Raja Grafindo Persada. Jakarta.

Syarief ANL, Lestari DAH, dan Kasymir E. 2019. Keragaan Agroindustri Kerupuk Bawang Winda Putri di Kecamatan Tanjung Senang Kota Bandar Lampung. Jurnal Ilmu Ilmu Agribisnis, 7 (3) : 298-305. https://jurnal.fp.unila.ac.id/index.php/JIA/artic le/viewFile/3766/2767 [5 Agustus 2020]. 